\title{
Donald T. Stuss
}

\section{$1941-2019$ \\ Craik, F., \& Levine, B. (2020). Donald T. Stuss (1941-2019). Canadian Psychology/Psychologie canadienne, 61(1), 92-93}

CCanadian Psychological Association, 2020. This paper is not the copy of record and may not exactly replicate the authoritative document published in the CPA journal. Please do not copy or cite without author's permission. The final article is available, upon publication, at: https://doi.org/10.1037/cap0000203

Canadians have contributed more than their fair share to neuropsychology. The work of Donald T. Stuss, OC, FRSC, who died in Toronto on September 3, 2019 of complications following pancreatic cancer was world-leading, but also notable for its influence on the landscape of Canadian neuroscience. Don's theoretical contributions to human frontal lobe function followed from the influential but painstaking focal lesion approach practiced by many great Canadian neuropsychologists (e.g., Milner, Hebb, Goodale). These contributions were matched by his impact as the founding Director of the Rotman Research Institute at Baycrest in Toronto and also the founding President of the Ontario Brain Institute. He is survived by his former wife Kaaren Stuss, his children David and Leanne Stuss and by his partner Lourenza Fourie.

Don Stuss was born in Sudbury and grew up in Kitchener, Ontario where his mother ran a small restaurant. His parents were immigrants from Ukraine and Don, a patriotic Canadian, remained proud of his Ukrainian roots throughout his life. He was deeply religious as a young man and after graduating from high school in 1959 entered a monastery in Alberta where he studied and worshipped for six years. After this period he decided that he wished to live a more active and engaged life so he left the monastery to study philosophy at the University of Ottawa and St. Paul's University. While his formal religious practice ended, his spirituality continued to guide his search for the neuroscientific origins of consciousness and humanity, and in his generous approach to those around him as he built world-leading institutes.

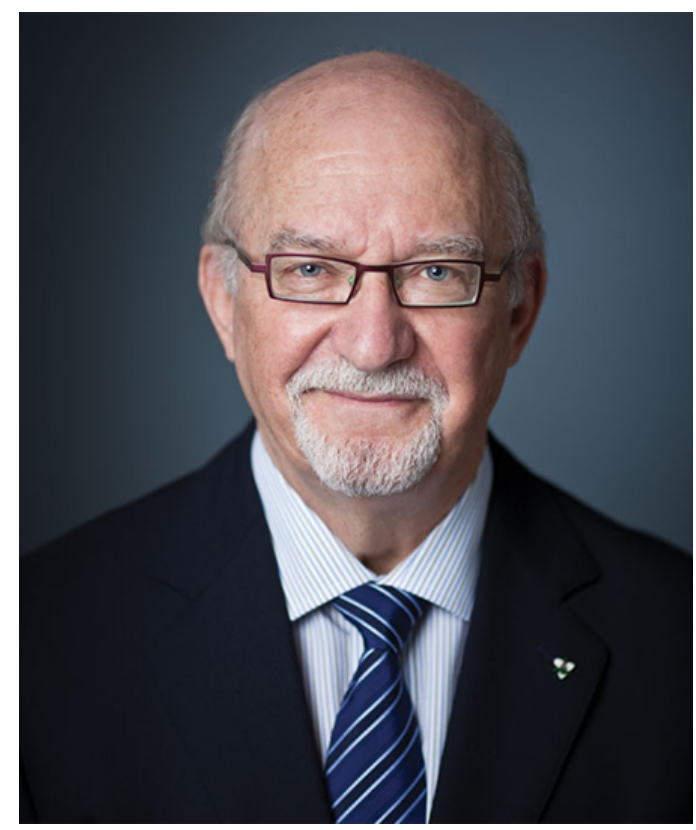

Don worked as a teacher and football coach at high schools in Ontario before returning to the University of Ottawa to pursue graduate studies in psychology; he obtained his $\mathrm{PhD}$ in 1976. 
After a postdoctoral position at the Boston VA, Don returned to Ottawa to pursue neuropsychological research at the University and also clinical work at the Ottawa General Hospital, where he served as Director of Clinical Neuropsychological Services from 1978 to 1989 and wrote the seminal 1986 volume, The Frontal Lobes, with Frank Benson. He moved to Toronto in 1989 when he was appointed as the first Director of the Rotman Research Institute (RRI), and later to the position of Vice-President of Research at Baycrest. At the RRI he continued his increasingly influential research on frontal lobes and their role in attention, memory and cognitive control. After stepping down from his position at Baycrest in 2010 he claimed that he had "retired," but was soon pressed into service again as the founding President of the Ontario Brain Institute (OBI) - an appointment influenced by his friend and mentor Joseph Rotman. Don finally did retire in 2016, but continued to be actively engaged in research and scholarly writing until a few months before he died at home in Toronto. His impressive legacy as a psychologist rests on his over 200 journal publications (cited 48,000 times), on his books (Stuss \& Benson, 1986; Stuss \& Knight, 2002, 2013), his numerous mentees, and on the ongoing success of the RRI and OBI.

Don had three major research interests in his scientific career: first, the functions of the frontal lobes and their role in cognitive processes, conscious awareness and feelings of self; second, the effects of traumatic brain injury on these functions; and third, improving clinical approaches to assessment and rehabilitation. Each of these was grounded in Don's thinking about functions of the frontal lobes in enabling cognitive processes and experiences in the normal adult, and how these functions are affected by focal and diffuse damage. While he was at the Boston VA, Don and Frank Benson completed a study of patients who had undergone prefrontal leucotomy in the 1950s. The follow-up was 25 years after surgery, and one of the interesting control groups was a group of individuals who had received the same initial clinical diagnosis, but who had not received prefrontal leucotomies. The results showed that the surgery had typically been successful in reducing or eliminating the original psychiatric symptoms, with minimal effects on cognitive measures such as IQ and basic attention. However, the surgery also resulted in many specific cognitive and social behaviour deficits whose nature depended on the exact location of the lesion. These observations formed the basis for a lifetime of research on selected focal lesion patients in order to specify the functions of different areas of the human frontal lobes. One major summary of the fractionation of the systems underlying executive control (Stuss \& Alexander, 2007) used a variety of experimental and clinical strategies to identify impairments in specific domains of attention associated with regionally specific frontal lesions. A similar approach to fractionating the processes involved in emotional control, social cognition and theory of mind was completed in parallel. The result of identifying specific regions associated with aspects of cognitive and emotional functioning is obviously of great importance, both for a fuller understanding of the links between brain and mind, and also as the basis for more theoretically driven, anatomically targeted and ecologically valid rehabilitation procedures. 
Don was known by many as warm and caring, a wonderful mentor with a great sense of fun who lived life to the fullest. Once you probed below the surface a little, however, Don was quite a complex character - his years in the monastery and as a high-school teacher left their mark on his personality (or perhaps his personality dictated these life choices). Beneath the fun and laughter, he took very seriously his obligations to his staff, to his family, and to society generally. He had strong and creative ideas about how to run a research institute, not just in terms of scientific excellence but also in terms of fostering a family feeling of involvement and commitment among the staff at all levels. Don began building the RRI with a nucleus of cognitive scientists, many drawn from the ranks of the University of Toronto's Psychology Department. From there he rapidly (but selectively) expanded the group to incorporate neuroimaging research as its importance rose, making the RRI a premier destination for trainees in cognitive neuroscience, many of whom went on to become leaders in their own right. Don indefatigably sought funding to build infrastructure - often roping in his grumbling colleagues to participate in yet another large grant or research project. But typically the grumbling turned first to grudging acknowledgement that it WAS a good idea after all, and then to eager participation. As President of the OBI, Don's vision expanded to form five integrated discovery platforms, bridging theoretical and applied neuroscience. To achieve his vision, Don mastered the skills of talking to (and persuading) politicians, high-level civil servants, hospital bosses and university administrators that his ideas were on the right lines and that his requests were reasonable. He was (mostly!) successful in exercising these new skills, although interactions were sometimes difficult and frustrating. But he made the model of OBI funding for brain research in Ontario a highly successful one that was emulated in other regions of the country and even internationally.

Don loved the Canadian landscape and rugged outdoor pursuits. Some early photographs show him stripped to the waist downing a beer in the backwoods, splitting logs with some bearded pals, and navigating white-water rapids in a canoe. He was deeply attached to his family cottage in the Kawarthas and insisted on going there for one last visit with Lourenza (including a last ritual dipping of his toes in the lake) only weeks before the end.

Don's success and influence as a researcher and scientific manager earned him many accolades and prestigious marks of recognition. These included being President of the International Neuropsychological Society, a member of the Order of Ontario, a Fellow of the Royal Society of Canada, and an Officer in the Order of Canada. Donald Stuss was a great neuropsychologist and also a great Canadian.

Fergus Craik and Brian Levine, Rotman Research Institute at Baycrest 